\title{
Morphology control and characterization of broom-like porous
}

\section{$\mathrm{CeO}_{2}$}

Bin Xu ${ }^{\text {a,b,c }}$, Qitao Zhang ${ }^{\text {a,b }}$, Saisai Yuan ${ }^{\text {a,b }}$, Ming Zhang ${ }^{\text {b,c * }}$,Teruhisa

$$
\text { Ohno, }, \text { a,d,e,f,* }
$$

${ }^{a}$ Department of Applied Chemistry, Faculty of Engineering, Kyushu Institute of Technology, Kitakyushu 804-8550, Japan

${ }^{\mathrm{b}}$ School of Chemistry and Chemical Engineering, Yangzhou University, Yangzhou 225002, China

c Test Center, Yangzhou University, Yangzhou 225002, China

${ }^{\mathrm{d}}$ JST, PRESTO and ACT-C, 4-1-8 Honcho Kawaguchi, Saitama 332-0012, Japan

e JST,ACT-C,4-1-8 Honcho Kawaguchi, Saitama 332-0012, Japan

${ }^{\mathrm{f}}$ Research Center for Advanced Eco-fitting Technology, Kyushu Institute of

Technology, Tobata, Kitakyushu 804-8550, Japan

*corresponding author. Tel: +81 93884 3318; Fax: +81 938843318

E-mail address: lxyzhangm@yzu.edu.cn (Ming Zhang)

tohno@che.kyutech.jp (T.Ohno) 


\section{ABSTRACT}

In this study, $\mathrm{CeO}_{2}$ with a broom-like porous hierarchical structure was successfully prepared by a simple template-free hydrothermal method. In the whole hydrothermal process, reaction time and temperature play important roles in morphology control. The morphology of the as-prepared samples was characterized by field emission scanning electron microscopy, transmission electron microscopy and high-resolution transmission electron microscopy. Structure information was obtained by using an X-ray diffractometer and Raman analysis. Analyses of elements and chemical valence analysis were carried on X-ray photoelectron spectroscopy. Absorption edge and band gap energy were investigated by UV-vis diffuse reflectance. In addition, the optimum experimental conditions for target products were determined. Compared with various morphology samples’ BET data, relative intensity of Raman peaks, catalytic evaluation, we can draw a conclusion that $\mathrm{CeO}_{2}$ with a broom-like porous hierarchical structure has a higher concentration of oxygen vacancies that results in enhancement of catalytic activity. An Ostwald ripening process with orientative self-assembly was proposed for formation of the broom-like porous hierarchical structure.

Keywords: $\mathrm{CeO}_{2}$ nanoparticles, hierarchical structure, porous, oxygen vacancy, morphology control 


\section{Introduction:}

Cerium is one of the most important rare earth elements due to its promising optical [1-4], magnetic [1, 5-7] and electrical [8-11] performance, which is attributed to cerium's 4f orbital having an unpaired electron [12-14], cerium's atomic magnetic distance being large, its electron energy level being extremely high, and the fact that cerium can react with most of the elements to form multi-valence and multi-coordination compounds [15]. As a significant rare earth oxide, ceria has attracted great attention due to its remarkable redox properties [16] and its oxygen storage and release capability (OSC) via facile conversion between $\mathrm{Ce}^{3+}$ and $\mathrm{Ce}^{4+}$ oxidation states [17]. It has been utilized in many practical applications such as polishing materials [18], solar cells [19], and ultraviolet blocking materials [20, 21].

Various methods, including thermal evaporation [22], coprecipitation [23], electrospinning (ESP) [24], and the sol-gel technique [25], have been widely utilized for the fabrication of $\mathrm{CeO}_{2}$ with various morphologies. Recent research has revealed that excellent catalytical performance and easy functionalization of $\mathrm{CeO}_{2}$ materials are influenced by their structural properties [26]. For instance, our team have successfully fabricated a sesame ball-like $\mathrm{CeO}_{2}$ : a $\mathrm{Y3}+\mathrm{P}(\mathrm{St}-\mathrm{AA})$ composite microsphere [27]. Compared with conventional one-dimensional (1D) nanowires, nanorods and nanocubes as well as nanoparticles with other shapes, $\mathrm{CeO}_{2}$ with a newly constructed three-dimensional (3D) hierarchical architecture would acquire some special properties that $\mathrm{CeO}_{2}$ with a single $1 \mathrm{D}$ morphology does not possess. Although some progress has been made in the fabrication of $3 \mathrm{D}$ hierarchical 
architectures composed of a 1D nanostructure, the methods for fabrication usually need special templates through a complex experimental course. For example, Titrical et al. prepared a $\mathrm{CeO}_{2}$ hollow sphere using carbon D-glucose as a template [28]. Leandro Gonza'lez-Rovira et al. used a porous alumina membrane as a template to synthesize $\mathrm{CeO}_{2}$ nanotubes [29]. However, to the best of our knowledge, there has been no report about broom-like porous $\mathrm{CeO}_{2}$ obtained by one-step controlled synthesis.

Herein, we report for the first time a facile and feasible approach to prepare broom-like porous $\mathrm{CeO}_{2}$ by a simple template-free hydrothermal technique. The morphology of $\mathrm{CeO}_{2}$ can be controlled by adjusting the reaction time, temperature and reactant concentration. Compared with traditional $\mathrm{CeO}_{2}$ with a $1 \mathrm{D}$ morphology structure, catalytic activities of the target products were enhanced.

\section{Experiment section}

\subsection{Materials}

Dihydrate trisodium citrate $\left(\mathrm{C}_{6} \mathrm{H}_{5} \mathrm{Na}_{3} \mathrm{O}_{7} \cdot 2 \mathrm{H}_{2} \mathrm{O}\right)$, urea and cerium nitrate hexahydrate $\left(\mathrm{Ce}\left(\mathrm{NO}_{3}\right)_{3} \cdot 6 \mathrm{H}_{2} \mathrm{O}\right)$ were of analytical grade and used without any further purification. All of the above original materials were purchased from Wako Co., Ltd.

\subsection{Preparation}

A typical synthetic procedure is as follows. First, $5.88 \mathrm{~g}$ dihydrate trisodium citrate $\left(\mathrm{C}_{6} \mathrm{H}_{5} \mathrm{Na}_{3} \mathrm{O}_{7} \cdot 2 \mathrm{H}_{2} \mathrm{O}\right)$ (DTC) was dissolved in $80 \mathrm{ml}$ deionized water with vigorous magnetic stirring at room temperature. Ten minutes later, $2.4 \mathrm{~g}$ urea was added to the solution. The homogeneous mixture was prepared for further use. At the 
same time, $1.63 \mathrm{~g}$ cerium nitrate hexahydrate $\left(\mathrm{Ce}\left(\mathrm{NO}_{3}\right)_{3} \cdot 6 \mathrm{H}_{2} \mathrm{O}\right)$ was dissolved in 20 ml deionized water with vigorous magnetic stirring at room temperature. Then the cerium nitrate aqueous solution was dropped into the above mixture step by step, and the mixture was stirred for 30 min until the solution changed to a faint yellow color. The mixed solution was then sealed in a $100 \mathrm{ml}$ Teflon-lined autoclave and heated at $100,120,150,180^{\circ} \mathrm{C}$ for $12,24,39,48$ hours, respectively. After cooling to room temperature naturally, a white precipitate was collected by centrifugation and washed with deionized water and ethanol respectively at least three times. Ceria was obtained by calcination of the as-prepared precursor in air at $500{ }^{\circ} \mathrm{C}$ for $4 \mathrm{~h}$.

\subsection{Characterizations}

Morphology and size of the products were examined by an FE-SEM (Hitachi, S-4800, 15KV) and HR-TEM (FEI, Tecnai G2 F30 S-TWIN, 300KV). XRD patterns of the products were obtained on a Bruker-AXS X-ray equipped with graphite monochromator and CuKa radiation ( $\lambda=1.5406 \AA$ ). The crystallite parameters and size were calculated by the Rietveld method (TOPAS 4.0). $\mathrm{N}_{2}$ adsorption and desorption isotherms were recorded at $77 \mathrm{~K}$ using a Nova 4200e instrument. The samples were precisely weighted and degased at $373 \mathrm{~K}$ for $3 \mathrm{~h}$. The specific surface area was calculated by the 5 points Brunauer-Emmit-Teller theory. Raman analysis (Renishaw, In via) was performed using a $532 \mathrm{~nm}$ excitation laser with $5 \mathrm{~mW}$ and an air-cooled CCD detector. Raman peak shifts were determined by fitting with the Lorentzian and Gaussian composite function. Absorption edge and band gap energy were investigated by using a UV-vis diffuse reflectance spectral (Varian, Cary 5000). 
An x-ray photoelectron spectroscopy (XPS) experiment was carried on a Shimadzu KRATOS AXIS-NOVA system at room temperature under $10^{-9}$ pa using $\mathrm{Al} \mathrm{K}_{\alpha}$ radiation and $\mathrm{Au}$ 4f peak (83.8 eV) reference. Temperature-programmed reduction (TPR) experiments were performed on FTNESORB-3010 using $10 \% \mathrm{H}_{2}$ in air as the analytic gas, with a flow of $50 \mathrm{~cm}^{3} / \mathrm{min}$ over a temperature range of $50-700{ }^{0} \mathrm{C}$. A sample mass of ca. $500 \mathrm{mg}$ was pretreated by calcinated at $200{ }^{0} \mathrm{C}$ for $1 \mathrm{~h}$ and subsequently cooled to100 ${ }^{0} \mathrm{C}$ under an Ar flow before being used. The consumption of $\mathrm{H}_{2}$ was monitored by a thermal conductivity detector (TCD) operating at $60{ }^{\circ} \mathrm{C}$ and 80mA.

\section{Results and discussion}

\subsection{Morphology characterization}

The morphology of as-prepared $\mathrm{CeO}_{2}\left(\mathrm{DTC}: \mathrm{Ce}=1.3: 1 / 120^{\circ} \mathrm{C}\right)$ with different reaction times were investigated by the FE-SEM and HR-TEM. Fig.1.(a)-(d) show FE-SEM images of $\mathrm{CeO}_{2}$ nanoparticles with a hierarchical structure and the formation course of the broom-like porous $\mathrm{CeO}_{2}$. Fig.1.(a) shows the morphology of individual flower-like $\mathrm{CeO}_{2}$ at $12 \mathrm{~h}$ with diameters of almost $5 \mu \mathrm{m}$ and with each petal thickness being approximately $50 \mathrm{~nm}$. The inset image (Fig. 1(A)) displays clear lattice fringes with interplanar spacing of $0.32 \mathrm{~nm}$ that were assigned to the $\mathrm{CeO}_{2}(111)$ crystal plane. Fig.1.(b)-(d) show that morphology transformed with increase in reaction time. The shape changed to a broom-like shape with an average diameter of $4 \mu \mathrm{m}$. Numerous nanorods are connected at one end and diverge at the other end to form a broom-like hierarchical architecture. The nanorods have uniform diameters of $200 \mathrm{~nm}$ and lengths 
of $4 \mu \mathrm{m}$. In addition, smoothness of the surfaces of nanorods was improved by the increasing time. Fig.1.(B) shows an HR-TEM image of an as-fabricated sample at 24 hours. The smallest unit of morphology is ceria nanoparticles of about $10 \mathrm{~nm}$ in diameter. Nanoparticles aggregate with orientation to form a porous nanorod with an internal diameter of $20 \mathrm{~nm}$. The interplanar spacing of $0.32 \mathrm{~nm}$ is equal to the bulk $\mathrm{CeO}_{2}$ (111), indicating that the crystal lattice does not expand or contract, although the morphology changed to a porous broom-like structure. Compared with the image in Fig. 1 (b) and (B), the rod surface has become much smoother and the particle size decreased to $5 \mathrm{~nm}$ obviously. At the same time, a porous structure still exists with internal size of pores remaining unchanged (Fig 1(c) and Fig. 1(C)). Fig. 1(d) shows a broom-like hierarchical architecture with a glossy surface after reaction for 48 hours. However, a porous structure is no longer observed. The nanorod morphology can be clearly observed in the inset image of Fig. 1(d). $\mathrm{CeO}_{2}$ nanoparticles spontaneously assembled to become a hexagonal-prisms nanorods aggregate structure. This transformation course is discussed in the section on the fabrication mechanism. The effects of other experimental parameters, including reaction temperature and original material stoichiometry, are showed in supplementary information (see the Fig. S1 and S2).

\subsection{Structure analysis}

Fig. 2 (a)-(b) shows XRD patterns of $\mathrm{CeO}_{2}$ prepared under different experimental conditions. Characteristic peaks at 28.5, 33.047 .4 and $56.32 \theta$ are attributed to pure cerium oxide with a cubic fluorite structure (JCPDS No. 34-0394) 
and are assigned to the crystal planes (111), (200), (220) and (311), respectively. The sharp diffraction peaks from both samples suggest a high degree of crystallinity of the fabricated $\mathrm{CeO}_{2}$ nanocrystal, and no impurity peaks appeared, indicating that reaction time, temperature and mole ratio of original materials have no effect on $\mathrm{CeO}_{2}$ crystalline phase purity. The relative intensity between characteristic peaks at 28.5, 33.0 47.4 and $56.32 \theta$ does not change clearly, suggesting that there is no preferred orientation or that crystal orientation growth did not occur. However, the strongest diffraction peak at 28.5 (111) shows clear changes in intensity and peak shape with increase in reaction time (see the Fig. 2(a)). Compared with other reaction times, the full width at half maximum (FWHM) value reaches the maximum at 39 hours, indicating that the smallest particle size of the product was obtained at that time according to the Scherrer equation. This phenomena did not been observed in other diffraction lines changed with reaction temperature and original materials stoichiometry (Fig. 2(b) and Fig S3), indicating that reaction time have a strong effect on the morphology and particle size of products. This result is consistent with Rietveld refinement results and with the FE-SEM and HR-TEM observations.

Rietveld refinements were also carried out according to the diffraction lines by varying parameters [30] such as background, unit cell, and isotropic thermal parameters and could obtain the results such as crystal lattice value, grain size, atom position and occupancy. Fig. 2(d) demonstrated the difference in product (mole ratio DTC: $\mathrm{Ce}=1.3: 1$ and reaction at $120{ }^{0} \mathrm{C}$ for $39 \mathrm{~h}$ ) between the calculated value and measured data by the TOPAS 4.0. The calculated lattice parameter (a) is 
approximately $0.542 \mathrm{~nm}$ and the average grain size is $4.5 \mathrm{~nm}\left(\mathrm{R}_{\mathrm{wp}}=2.36 \%\right) . \mathrm{R}_{\mathrm{wp}}$ value was below five percent, indicating that the calculated value is correct and credible. Although the as-fabricated sample has the same space group with bulk $\mathrm{CeO}_{2}$ (Space Group: Fm-3m (No.225)), lattice parameter (a) shows small changes compared with the standard value $(0.541 \mathrm{~nm})$. The expansion of lattice parameter (a) indicated the reduction of $\mathrm{Ce}^{4+}$ to $\mathrm{Ce}^{3+}[31,32]$. The inset graph shows the true structure according to the results of calculation. Each cerium atom is surrounded by eight oxygen atoms and shows a standard $\mathrm{MO}_{8}$ type structure (FCC). The synthesized samples have similar structure under different experimental conditions, although the morphologies of the products have changed obviously. The calculated grain sizes and lattice parameters of as-fabricated products are summarized in Table 1.

Raman spectroscopy is considered to be a very facile and nonvolatile technique for characterization of ceria nanoparticles. In this study, we also investigated the oxygen vacancies of the prepared $\mathrm{CeO}_{2}$ by Raman technology Fig.3.(a) (b) and Fig. S4 show the recorded Raman spectra of the as-prepared products under different experimental conditions. A typical Raman shift at $\sim 460 \mathrm{~cm}^{-1}$ and a relatively weak shift at $\sim 600 \mathrm{~cm}^{-1}$ can be detected. The shift at $\sim 460 \mathrm{~cm}^{-1}$ can be assigned to F2g vibration of the fluorite-type structure and it can be considered as the symmetric stretching mode of oxygen atoms around cerium ions [33], and the molecule retains its tetrahedral symmetry throughout. Except for the strongest peak, a weak and less prominent band near $\sim 600 \mathrm{~cm}^{-1}$ can be founded which are assigned to the defect spaces which include oxygen vacancies[34, 35]. According to previous 
reports $[36,37]$ that not all cerium ions show $\mathrm{Ce}^{4+}$ chemical valence in the lattice and small cerium ions show $\mathrm{Ce}^{3+}$ tervalence [17]. In order to maintain the particles in an electrically neutral state, the lattice oxygen would escape from the structure and finally result in the formation of intrinsic oxygen vacancies. Many studies have shown that the presence of oxygen vacancies has a significant role in promoting adsorption and activation of $\mathrm{O}_{2}$, which may lead to improvement of the photocatalytic activity [17.32]. The integral area ratios of oxygen vacancy peak $\left(R_{D}\right)$ and $F 2 g$ are summarized in Table 1 . The value of $\mathrm{R}_{\mathrm{D}} / \mathrm{F} 2 \mathrm{~g}$ rapidly increased at first, reached a maximum at 39 hours, and then decreased with further increase in reaction time. $\mathrm{CeO}_{2}$ with a porous broom-like hierarchical architecture exhibits the highest value. The reason is that the basic unit of the target products is $\mathrm{CeO}_{2}$ nanoparticles with diameters of $5 \mathrm{~nm}$. As a consequence, this structure has a larger specific surface area (see Table 1) and higher oxygen vacancy concentration attribute to quantum size effect, and more activity oxygen exists on higher specific surface area [38]. Fig. 3(b) shows the Raman shifts and relativity intensity values of different reaction temperatures. The value of the integral area ratio of $R_{D}$ and F2g would increase with increase in hydrothermal temperature, although the F2g and $R_{D}$ shift were still at 460 $\mathrm{cm}^{-1}$ and $600 \sim \mathrm{cm}^{-1}$, respectively, indicating that a high temperature is beneficial for the formation of intrinsic oxygen vacancies. However, an entirely different phenomenon was observed from Fig. S5. The values $\left(\mathrm{R}_{\mathrm{D}} / \mathrm{F} 2 \mathrm{~g}\right)$ of as-fabricated samples with different original materials mole ratios were very similar, which may be 
due to morphologies did not change significantly and always maintains the bloom-like hierarchical structure.

\subsection{UV-vis diffuse reflectance spectra and band gap energy}

The UV-vis diffuse reflectance spectra of as-fabricated samples of different reaction times are shown in Fig. 4 (a). The optical band gap energy (Eg) can be calculated from the plot between $E=1240 / \lambda(\mathrm{nm})$ [39-41], where $\lambda$ is the wavelength corresponding to the absorption edge, and $[\mathrm{F}(\mathrm{R}) \mathrm{h} v]^{1 / 2}[42,43]$ as shown in Fig. 4 (b). Traditional bulk $\mathrm{CeO}_{2}$ has absorption at $\sim 380 \mathrm{~nm}$ and band gap energy at $3.20 \mathrm{eV}$, which originate from the charge transfer between $\mathrm{O}_{2 p}$ and $\mathrm{Ce}_{4 \mathrm{f}}$ states in $\mathrm{O}^{2-}$ and $\mathrm{Ce}^{4+}$ $[41,44]$. The absorption of products has a distinct shift to the visible region compared with $\mathrm{CeO}_{2}$ with a traditional $1 \mathrm{D}$ morphology structure. Subtle differences in band gap between various morphologies of broom-like ceria were detected from the plot of K-M curves. Fig. 4(b) shows the calculated energy gap value of samples $12 \mathrm{~h}, 24 \mathrm{~h}$, $39 \mathrm{~h}$ and $48 \mathrm{~h}$ and their $\mathrm{E}_{\mathrm{g}}$ values are $2.97 \mathrm{ev}, 3.06 \mathrm{ev}, 2.86 \mathrm{ev}$ and $3.04 \mathrm{ev}$, respectively. Obviously, the as-fabricated sample for 39h possess lower energy gap, indicating that $\mathrm{CeO}_{2}$ with a porous broom-like hierarchical structure can photogenerate more hole-electron pairs under visible-light irradiation. And the different band gap between the samples for $39 \mathrm{~h}$ and $24 \mathrm{~h}$ may attribute to oxygen vacancy[45-47]. Sample for $39 \mathrm{~h}$ possesses higher concentration of oxygen vacancy than 24h (see the table 1) and shows the red shift of band gap although they have similar broom-like morphology. Fig S5(a)-(b) and Fig S6(a)-(b) show UV-vis diffuse reflectance spectra and band gaps of as-fabricated samples under the conditions of different reaction temperatures and 
different mole ratios of the original materials, respectively. Compared with other reaction temperatures, the absorbance edge of the product fabricated at $120{ }^{0} \mathrm{C}$ shows a blue shift according to Fig S5 (a), which attribute to only broom-like morphology $\mathrm{CeO}_{2}$ obtained at $120{ }^{0} \mathrm{C}$. The shape of product is flower-like structure when reaction temperature is below $120{ }^{0} \mathrm{C}$, as well as only shuttle-like structure $\mathrm{CeO}_{2}$ can be detected when the temperature exceeded $120{ }^{\circ} \mathrm{C}$. The samples have similar band gap values $(\sim 3.0 \mathrm{eV})$ although the mole ratios of original materials have changed (see Fig S5 (b)). Therefore, the change in absorbance edge or band gap value may be caused by the change in morphology. These results are consistent with the results of Raman analysis, and this optical property is very important for good photocatalytic performance.

\subsection{X-ray photoelectron spectroscopy characterization}

Fig. 5(a) shows Ce 3d electron core level XPS spectra for as-fabricated samples and the change in the Ce $3 \mathrm{~d}_{3 / 2}$ and Ce $3 \mathrm{~d}_{5 / 2}$ components depending on the Ce3+ and Ce4+ oxidation states. Five pairs of doublets, $(\mathrm{u}, \mathrm{v}),\left(\mathrm{u}_{1}, \mathrm{v}_{1}\right),\left(\mathrm{u}_{2}, \mathrm{v}_{2}\right),\left(\mathrm{u}_{3}, \mathrm{v}_{3}\right)$ and $\left(\mathrm{u}_{0}\right.$, $\mathrm{v}_{0}$ ), can be decomposed from the origin region, where $\mathrm{u}$ and $\mathrm{v}$ come from Ce $3 \mathrm{~d}_{3 / 2}$ and Ce $3 d_{5 / 2}$ states, respectively. We observed that $(u, v),\left(u_{2}, v_{2}\right)$ and $\left(u_{3}, v_{3}\right)$, which were attributed to Ce $3 d^{9} 4 f^{2} O 2 p^{4}$, Ce $3 d^{9} 4 f^{1} O 2 p^{5}$ and Ce $3 d^{9} 4 f^{0} O 2 p^{6}$ final states, respectively, all belonged to the $\mathrm{Ce}^{4+}$ oxidation state. The two pairs doublets as $\left(\mathrm{u}_{1}, \mathrm{v}_{1}\right)$ and $\left(\mathrm{u}_{0}, \mathrm{v}_{0}\right)$ originated from the Ce $3 \mathrm{~d}^{9} 4 \mathrm{f}^{1} \mathrm{O} 2 \mathrm{p}^{4}$ and Ce $3 \mathrm{~d}^{9} 4 \mathrm{f}^{1} \mathrm{O} 2 \mathrm{p}^{5}$ final state, respectively, which correspond to the $\mathrm{Ce}^{3+}$ oxidation state. The relative amount of cerium in the tervalent oxidation state can be calculated from equation (1)[48]: 


$$
\frac{\left[\mathrm{Ce}^{3+}\right]}{\left[\mathrm{Ce}^{3+}+\mathrm{Ce}^{4+}\right]}=\frac{\operatorname{area}\left(V_{0}, V_{1}, U_{0}, U_{1}\right)}{\text { total area }}
$$

Results for oxidation states are summarized in the table S1. The fitting data demonstrated that the as-fabricated samples for different reaction time exhibits variation of $\left[\mathrm{Ce}^{3+}\right]$ concentration. Sample $39 \mathrm{~h}$ possesses about $22.5 \%$ of the cerium ions in the +3 state and this value is higher than the other samples.

Fig. 5(b) shows O 1s electron core level XPS spectra for as-fabricated samples with different reaction times. One peak around 529. 0eV with a shoulder around 531.1 $\mathrm{eV}$ can be clearly seen, and they can be attributed to lattice oxygen $\left(\mathrm{O}_{\text {lat }}\right)$ and surface active oxygen $\left(\mathrm{O}_{\text {sur }}\right)$, respectively. After deconvolution and multiple-peak separation, we could obtain the surface ratio from the equation (2):

$$
\frac{\left[\mathrm{O}_{\text {sur }}\right]}{\left[\mathrm{O}_{\text {sur }}+\mathrm{O}_{\text {lat }}\right]}=\frac{\text { area }\left(\mathrm{O}_{\text {sur }}\right)}{\text { total area }}
$$

Results for surface active oxygen are summarized in the table S1.Value of surface ratio for sample 39 hours is approximately $50.7 \%$ and this value is higher than others. The $\left[\mathrm{Ce}^{3+}\right]$ and $\left[\mathrm{O}_{\text {sur }}\right]$ concentration value of sample $39 \mathrm{~h}$ indicating that $\mathrm{CeO}_{2}$ with a porous broom-like structure should have higher surface active oxygen concentration and should have higher catalytic activity [49]. This result is well consistent with the $\mathrm{H}_{2}$-TPR characterization and Raman analysis.

\section{5 $\mathrm{H}_{2}$-TPR characterization}

Temperature-programmed reduction (TPR) in a flow of hydrogen up to $700{ }^{0} \mathrm{C}$ was used to characterize the catalysts and probe redox properties. Fig. 6(a) and (b) show the $\mathrm{H}_{2}$-TPR traces of as-fabricated samples under the condition of different reaction times and temperatures. The TPR trace of samples fabricated with different 
times at $120{ }^{\circ} \mathrm{C}$ (Fig. 6(a)) indicated a reduction behavior at around $450{ }^{\circ} \mathrm{C}$, which is attributed to the reduction of surface-capping oxygen of ceria [50]. The relatively moderate shift $\left(\sim 20{ }^{0} \mathrm{C}\right)$ of the main reduction peak to low temperature (ca. $430{ }^{0} \mathrm{C}$ ), relative to the profile of other samples, implies that the reducibility of sample fabricated after reaction for 39 hours has been considerably enhanced. The catalytic activity of $\mathrm{CeO}_{2}$ depended strongly on the morphology and crystal size [51], therefore $\mathrm{CeO}_{2}$ with a porous broom-like hierarchical structure and crystal size of about $5 \mathrm{~nm}$ would lead to the reducibility enhance. The TPR trace of samples fabricated at different temperatures for 24h (Fig. 6(b)) shows a similar reduction peak at around at $450{ }^{0} \mathrm{C}$, which is attributed to similar particle sizes although the morphology of products changed from flower-like and broom-like to shuttle-like. Although the morphology of products changed from flower-like and broom-like to shuttle-like with increasing reaction temperature, the particle size value of each product is very close (average particle size. $10 \mathrm{~nm}$ ). Consequently a broad reduction peak around at $450{ }^{0} \mathrm{C}$ can be detected.

\subsection{Mechanism for the fabrication of a porous broom-like $\mathrm{CeO}_{2}$ hierarchical architecture}

Results of systematic experiments showed that the reaction time and reaction temperature, as the key parameters, play a vital role in the fabrication of $\mathrm{CeO}_{2}$ with a broom-like porous hierarchical architecture. Based on the results of electron microscopy, we propose a new mechanism for the formation of broom-like porous 
$\mathrm{CeO}_{2}$. The mechanism is an Ostwald ripening process [52-54] coupled with crystal growth as schematically illustrated in Scheme 1.

At first, numerous nanocrystals form in the solution via crystallization. As the reaction process progresses, these nanocrystals self-assemble orientationally as nanorods with the aid of sodium citrate. Because of this kind of selected adsorption can effectively reduce the surface energy through increase specific surface area. When the reaction time was less than 24 hours, the nanorods coalesced together in a divergent form. This kind of coalescent resulted in the formation of flower-shaped morphology owing to the large interspaces between aggregated nanorods. As the Ostwald ripening process progresses, many nanocrystals are formed and self-assembled on the nanorod surface. The outer nanoparticles become larger, while the inner nanoparticles become smaller and finally they disappear due to the crystal concentration difference between the outer and inner parts of the nanorod [35]. Then a nanorod with a porous structure is formed. At the same time, the interspaces between the rods gradually shrink, and the rods become close to each other. A broom-like porous structure is formed at this stage. When the reaction time was 24 hours, the quantity of outer large particles was much more than inner small particles, the average particle size reached about $10 \mathrm{~nm}$. And when the reaction time was 39 hours, more new small particles will growth on rod surface which resulted in the average particle size decreased again. That's the reason the sample $24 \mathrm{~h}$ and $39 \mathrm{~h}$ present differential properties although they possess similar A broom-like porous structure. With further increase in the reaction time, the particles become large enough to completely fill the 
formed porous structure. Therefore, with a long reaction time, only a broom-like structure without a porous morphology could be obtained.

\section{Conclusions}

In summary, a broom-like porous $\mathrm{CeO}_{2}$ hierarchical architecture was successfully prepared by a simple hydrothermal method. The Ostwald ripening theory could explain the morphology evolution process. The optimum reaction time and temperature for the synthesis of porous broom-like $\mathrm{CeO}_{2}$ was found to be 39 hours and $120{ }^{\circ} \mathrm{C}$, respectively. This method for synthesis is effective and reproducible and can be further expanded to fabricate other morphology-controlled inorganic nanoparticles. The results of H2-TPR, XPS, Raman and BET analyses demonstrated the $\mathrm{CeO}_{2}$ with a porous broom-like has an advantage for catalytic activity. Consequently, the as-synthesized broom-like porous $\mathrm{CeO}_{2}$ is a promising material for practical application in photocatalytic materials and SOFCs as well as other new environment-friendly materials.

\section{Acknowledgements}

This work was supported by the JST PRESTO program and JST ACT-C program. The authors are grateful for financial support from the National Natural Science Foundation of China (No. 50873085)

\section{References}

[1] M. Taguchi, S. Takami, T. Naka, T. Adschiri, Crystal Growth \& Design, 9 (2009) 5297-5303. 
[2] G.I.N. Waterhouse, J.B. Metson, H. Idriss, D. Sun-Waterhouse, Chemistry of Materials, 20 (2008) 1183-1190.

[3] X. Xu, Z. Saghi, G. Yang, R.J. Hand, G. Möbus, Crystal Growth \& Design, 8 (2008) 1102-1105.

[4] N. Wetchakun, S. Chaiwichain, B. Inceesungvorn, K. Pingmuang, S. Phanichphant, A.I. Minett, J. Chen, ACS Applied Materials \& Interfaces, 4 (2012) 3718-3723.

[5] S.-Y. Chen, K.-W. Fong, T.-T. Peng, C.-L. Dong, A. Gloter, D.-C. Yan, C.-L. Chen, H.-J. Lin, C.-T. Chen, The Journal of Physical Chemistry C, 116 (2012) 26570-26576. [6] K.V. Hoecke, J.T.K. Quik, J. Mankiewicz-Boczek, K.A.C.D. Schamphelaere, A. Elsaesser, P.V.d. Meeren, C. Barnes, G. McKerr, C.V. Howard, D.V.D. Meent, K. Rydzyński, K.A. Dawson, A. Salvati, A. Lesniak, I. Lynch, G. Silversmit, B.D. Samber, L. Vincze, C.R. Janssen, Environmental Science \& Technology, 43 (2009) 4537-4546.

[7] C. Ma, D. Wang, W. Xue, B. Dou, H. Wang, Z. Hao, Environmental Science \& Technology, 45 (2011) 3628-3634.

[8] Z.L. Wang, X. Feng, The Journal of Physical Chemistry B, 107 (2003) 13563-13566.

[9] X.D. Zhou, W. Huebner, H.U. Anderson, Chemistry of Materials, 15 (2002) 378-382.

[10] P. Bera, A. Gayen, M.S. Hegde, N.P. Lalla, L. Spadaro, F. Frusteri, F. Arena, The Journal of Physical Chemistry B, 107 (2003) 6122-6130.

[11] S. Kim, J.S. Lee, C. Mitterbauer, Q.M. Ramasse, M.C. Sarahan, N.D. Browning, 
H.J. Park, Chemistry of Materials, 21 (2009) 1182-1186.

[12] V. Matolín, L. Sedláček, I. Matolínová, F. Šutara, T. Skála, B. Šmíd, J. Libra, V.

Nehasil, K.C. Prince, The Journal of Physical Chemistry C, 112 (2008) 3751-3758.

[13] F. Yang, Y. Choi, S. Agnoli, P. Liu, D. Stacchiola, J. Hrbek, J.A. Rodriguez, The Journal of Physical Chemistry C, 115 (2011) 23062-23066.

[14] B.M. Reddy, A. Khan, Y. Yamada, T. Kobayashi, S. Loridant, J.-C. Volta, Langmuir, 19 (2003) 3025-3030.

[15] J.P.Y. Tan, H.R. Tan, C. Boothroyd, Y.L. Foo, C.B. He, M. Lin, The Journal of Physical Chemistry C, 115 (2011) 3544-3551.

[16] K. Zhou, Z. Yang, S. Yang, Chemistry of Materials, 19 (2007) 1215-1217.

[17] H. Imagawa, A. Suda, K. Yamamura, S. Sun, The Journal of Physical Chemistry C, 115 (2011) 1740-1745.

[18] L. Yan, R. Yu, J. Chen, X. Xing, Crystal Growth \& Design, 8 (2008) 1474-1477.

[19] R.K. Pati, I.C. Lee, K.J. Gaskell, S.H. Ehrman, Langmuir, 25 (2008) 67-70.

[20] Z.-L. Wang, G.-R. Li, Y.-N. Ou, Z.-P. Feng, D.-L. Qu, Y.-X. Tong, The Journal of Physical Chemistry C, 115 (2010) 351-356.

[21] Z. Wang, Z. Quan, J. Lin, Inorganic Chemistry, 46 (2007) 5237-5242.

[22] C. Paun, O.V. Safonova, J. Szlachetko, P.M. Abdala, M. Nachtegaal, J. Sa, E. Kleymenov, A. Cervellino, F. Krumeich, J.A. van Bokhoven, The Journal of Physical Chemistry C, 116 (2012) 7312-7317.

[23] M. Jobbágy, F. Mariño, B. Schönbrod, G. Baronetti, M. Laborde, Chemistry of Materials, 18 (2006) 1945-1950. 
[24] L. Xu, H. Song, B. Dong, Y. Wang, J. Chen, X. Bai, Inorganic Chemistry, 49 (2010) 10590-10597.

[25] H. Xiao, Z. Ai, L. Zhang, The Journal of Physical Chemistry C, 113 (2009) 16625-16630.

[26] F. Dvořák, O. Stetsovych, M. Steger, E. Cherradi, I. Matolínová, N. Tsud, M.

Škoda, T. Skála, J. Mysliveček, V. Matolín, The Journal of Physical Chemistry C, 115 (2011) 7496-7503.

[27] Q. Zhang, B. Xu, S. Yuan, M. Zhang, T. Ohno, Materials Letters, 121 (2014) 109-112.

[28] M.-M. Titirici, M. Antonietti, A. Thomas, Chemistry of Materials, 18 (2006) 3808-3812.

[29] L. González-Rovira, J.M. Sánchez-Amaya, M. López-Haro, E. del Rio, A.B. Hungría, P. Midgley, J.J. Calvino, S. Bernal, F.J. Botana, Nano Letters, 9 (2009) $1395-1400$.

[30] J. Ciston, R. Si, J.A. Rodriguez, J.C. Hanson, A. Martínez-Arias, M. Fernandez-García, Y. Zhu, The Journal of Physical Chemistry C, 115 (2011) 13851-13859.

[31] F. Zhang, S.-W. Chan, J.E. Spanier, E. Apak, Q. Jin, R.D. Robinson, I.P. Herman, Cerium oxide nanoparticles: Size-selective formation and structure analysis, Applied Physics Letters, 80 (2002) 127.

[32] X.D. Zhou, W. Huebner, Applied Physics Letters, 79 (2001) 3512.

[33] H. Li, A. Petz, H. Yan, J.C. Nie, S.n. Kunsági-Máté, The Journal of Physical 
Chemistry C, 115 (2011) 1480-1483.

[34] Z.D. Dohčević-Mitrovi, M. Grujić-Brojčin, M. Šćepanović, Z.V. Popović, S. Bošković, B. Matović, M. Zinkevich, F. Aldinger, Condensed Matter, 18 (2006) S2061-S2068.

[35] K.C.H. J. R. McBride, B. D. Poindexter, and W. H. Weber, Journal of Applied Physics, 76 (1994) 2435.

[36] Y. Lee, G. He, A.J. Akey, R. Si, M. Flytzani-Stephanopoulos, I.P. Herman, Journal of the American Chemical Society, 133 (2011) 12952-12955.

[37] S. Chang, M. Li, Q. Hua, L. Zhang, Y. Ma, B. Ye, W. Huang, Journal of Catalysis, 293 (2012) 195-204.

[38] H. Rotter, M.V. Landau, M. Carrera, D. Goldfarb, M. Herskowitz, Applied Catalysis B: Environmental, 47 (2004) 111-126.

[39] P. Ji, J. Zhang, F. Chen, M. Anpo, The Journal of Physical Chemistry C, 112 (2008) 17809-17813.

[40] J. Li, G. Lu, H. Li, Y. Wang, Y. Guo, Y. Guo, Journal of Colloid and Interface Science, 360 (2011) 93-99.

[41] S. Guo, H. Arwin, S.N. Jacobsen, K. Jarrendahl, U. Helmersson, Journal of Applied Physics, 77 (1995) 5369-5376.

[42] Y. Park, S.K. Kim, D. Pradhan, Y. Sohn, Chemical Engineering Journal, 250 (2014) 25-34.

[43] C. Karunakaran, P. Gomathisankar, ACS Sustainable Chemistry \& Engineering, 1 (2013) 1555-1563. 
[44] J. Wang, D.N. Tafen, J.P. Lewis, Z. Hong, A. Manivannan, M. Zhi, M. Li, N. Wu, Journal of the American Chemical Society, 131 (2009) 12290-12297.

[45] B. Choudhury, A. Choudhury, Materials Chemistry and Physics, 131 (2012) 666-671.

[46] P. Patsalas, S. Logothetidis, C. Metaxa, Applied Physics Letters, 81 (2002) 466.

[47] B. Tatar, E.D. Sam, K. Kutlu, M. Ürgen, Journal of Materials Science, 43 (2008) 5102-5108.

[48] Y.V.f. Holger Borchert, Vasiliy V.Kaichev, Igor P.Prosvirin, J.phys. chem.B, 109 (2005) 5728-5738.

[49] L. Ma, D. Wang, J. Li, B. Bai, L. Fu, Y. Li, Applied Catalysis B: Environmental, 148-149 (2014) 36-43.

[50] N. Imanaka, T. Masui, K. Minami, K. Koyabu, Chemistry of Materials, 17 (2005) 6511-6513.

[51] H. Zhu, Z. Qin, W. Shan, W. Shen, J. Wang, Journal of Catalysis, 225 (2004) 267-277.

[52] P.X. Huang, F. Wu, B.L. Zhu, X.P. Gao, H.Y. Zhu, T.Y. Yan, W.P. Huang, S.H. Wu, D.Y. Song, The Journal of Physical Chemistry B, 109 (2005) 19169-19174.

[53] M. Lin, Z.Y. Fu, H.R. Tan, J.P.Y. Tan, S.C. Ng, E. Teo, Crystal Growth \& Design, 12 (2012) 3296-3303.

[54] G. Chen, C. Xu, X. Song, S. Xu, Y. Ding, S. Sun, Crystal Growth \& Design, 8 (2008) 4449-4453. 


\section{Figure captions}

Fig.1: FE-SEM and HR-TEM images of as-fabricated samples (DTC:Ce=1.3:1 $/ 120^{\circ} \mathrm{C}$ ) with different reaction times: (A)-(a) 12 hours, (B)-(b) 24 hours, (C)-(c) 39 hours, and (D) -(d) 48 hours.

Fig.2: XRD patterns of as-fabricated samples: (a) (DTC:Ce $=1.3: 1 / 120^{\circ} \mathrm{C}$ ) different reaction times, (b) (DTC:Ce=1.3:1/24h) different reaction temperatures, and (c) Rietveld refinement spectra.

Fig.3: Raman spectra of as-fabricated samples: (a) (DTC:Ce $=1.3: 1 / 120^{\circ} \mathrm{C}$ ) different reaction times and (b) (DTC:Ce=1.3:1 /24h) different reaction temperatures.

Fig.4: (a) UV-vis diffuse reflectance spectra and (b) band gaps of samples (DTC:Ce $=1.3: 1 / 120^{\circ} \mathrm{C}$ ) with different reaction times.

Fig.5: (a) Ce 3d core level XPS spectra of as-fabricated samples (DTC:Ce=1.3:1, $120{ }^{\circ} \mathrm{C}, 39 \mathrm{~h}$ ) and (b) O1s core level XPS spectra of as-fabricated samples (DTC:Ce $=1.3: 1 / 120^{\circ} \mathrm{C}$ ) with different reaction times.

Fig.6: H2-TPR profiles of as-fabricated samples: (a) (DTC:Ce=1.3:1 $\left./ 120^{\circ} \mathrm{C}\right)$ different reaction times and (b) (DTC:Ce=1.3:1 /24h) different reaction temperatures.

Scheme 1: Schematic illustration of the Ostwald ripening process of the porous broom-like $\mathrm{CeO}_{2}$.

Table. 1: Relevant data of as-fabircated samples used in the work. 

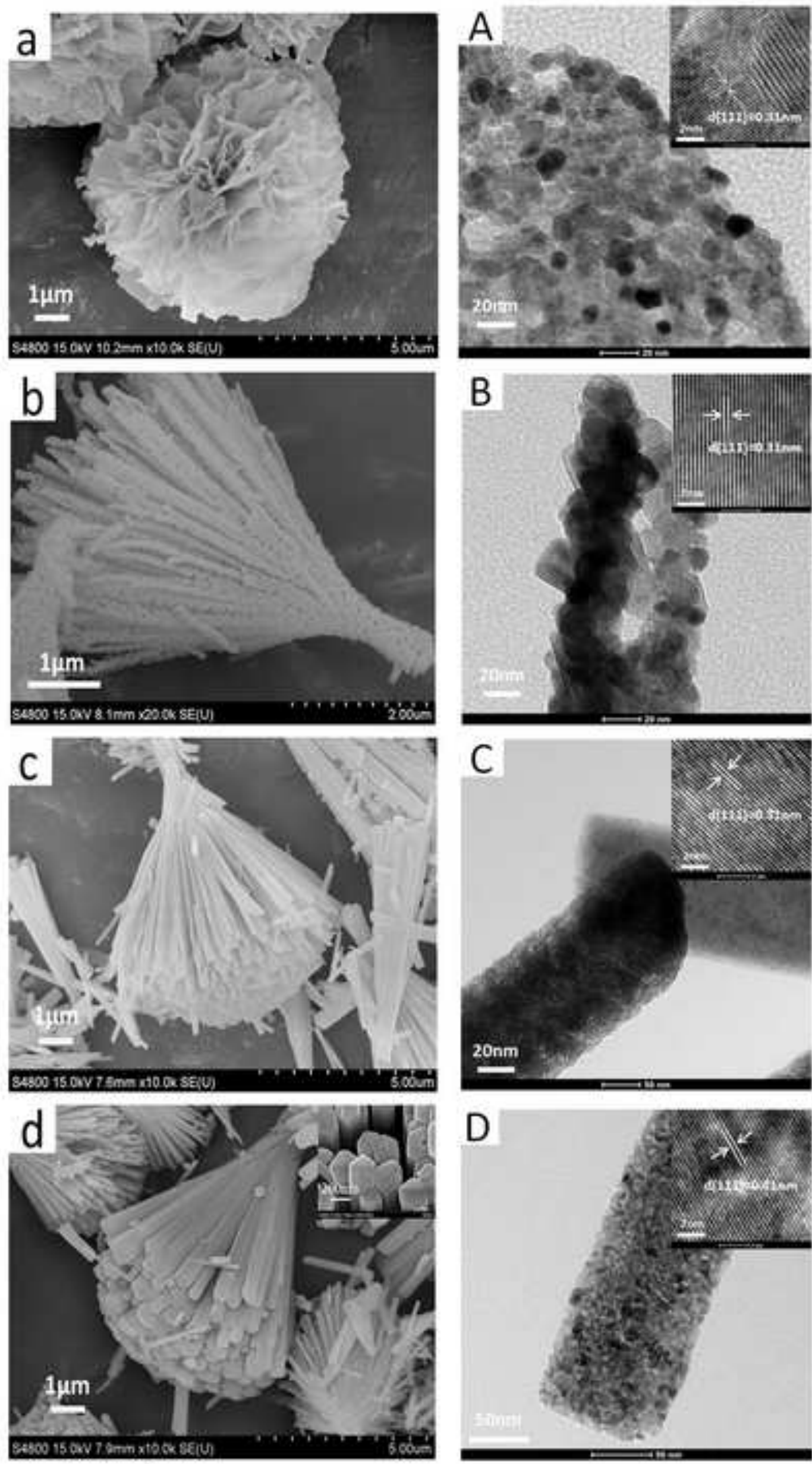

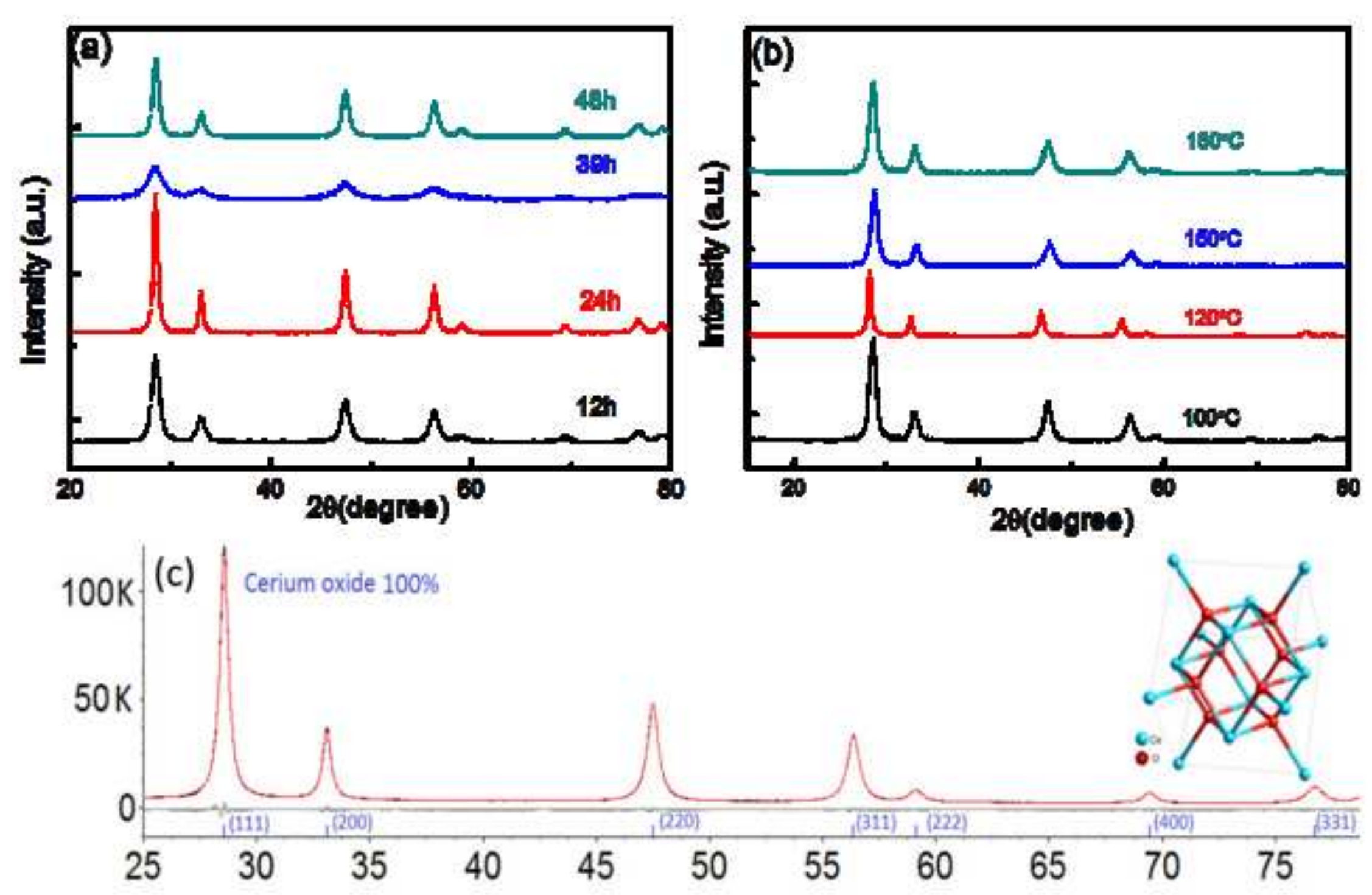

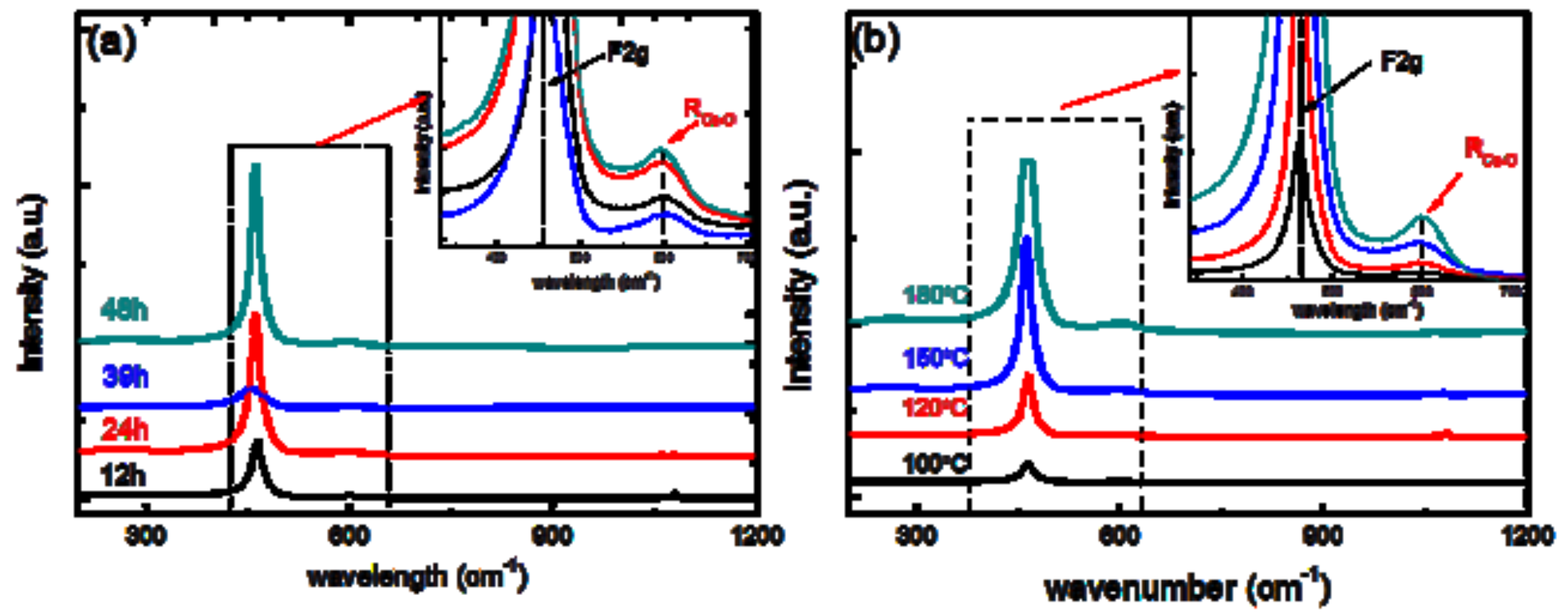

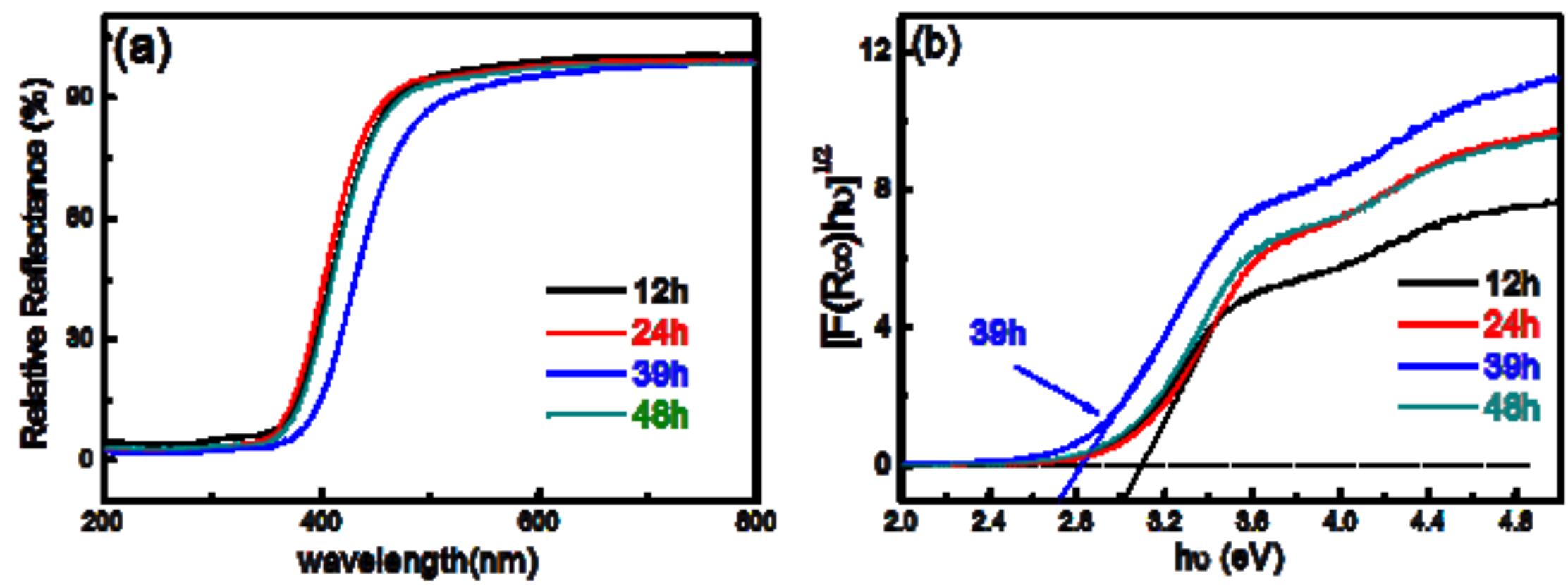

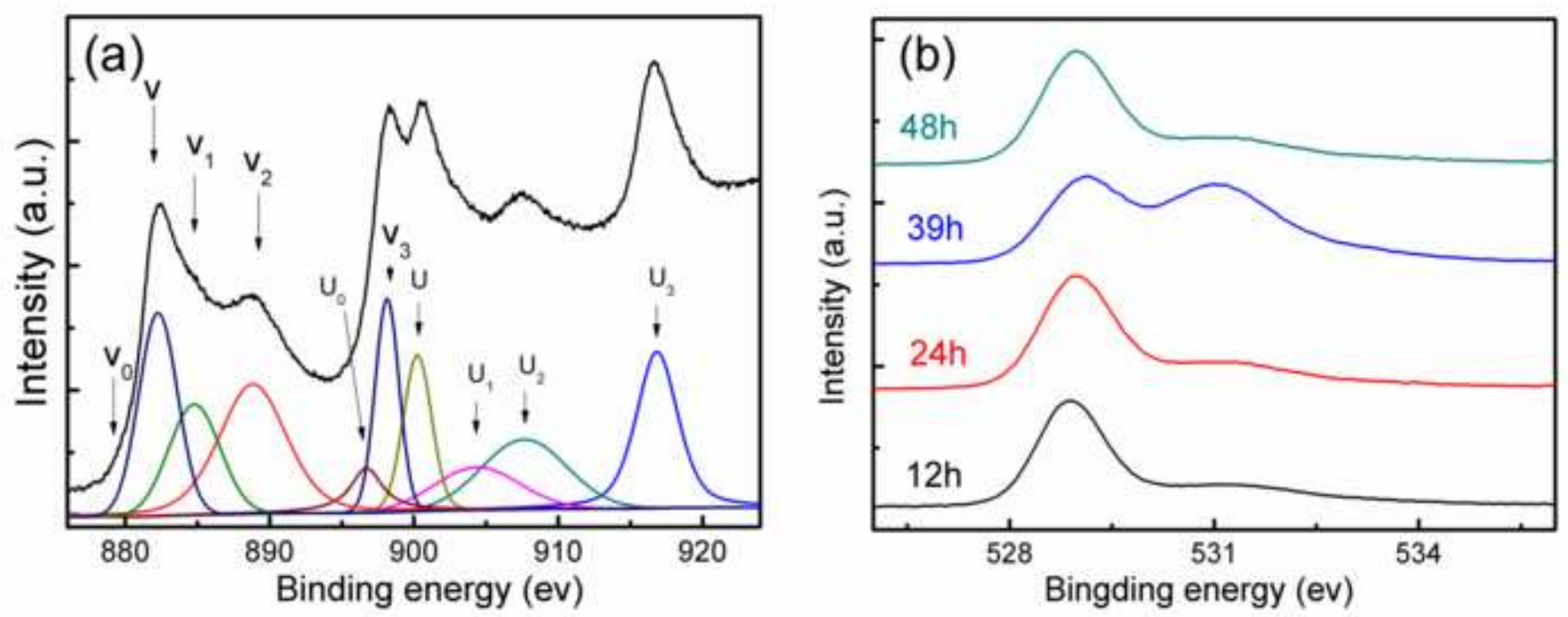

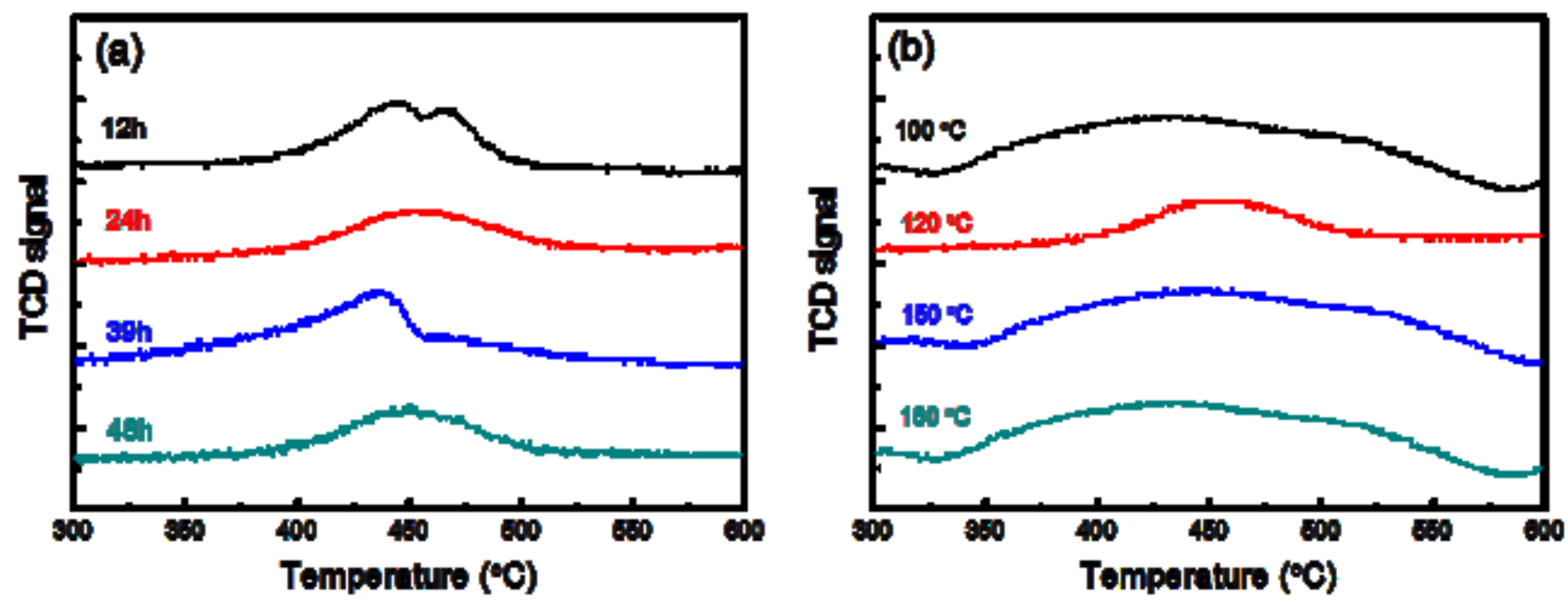


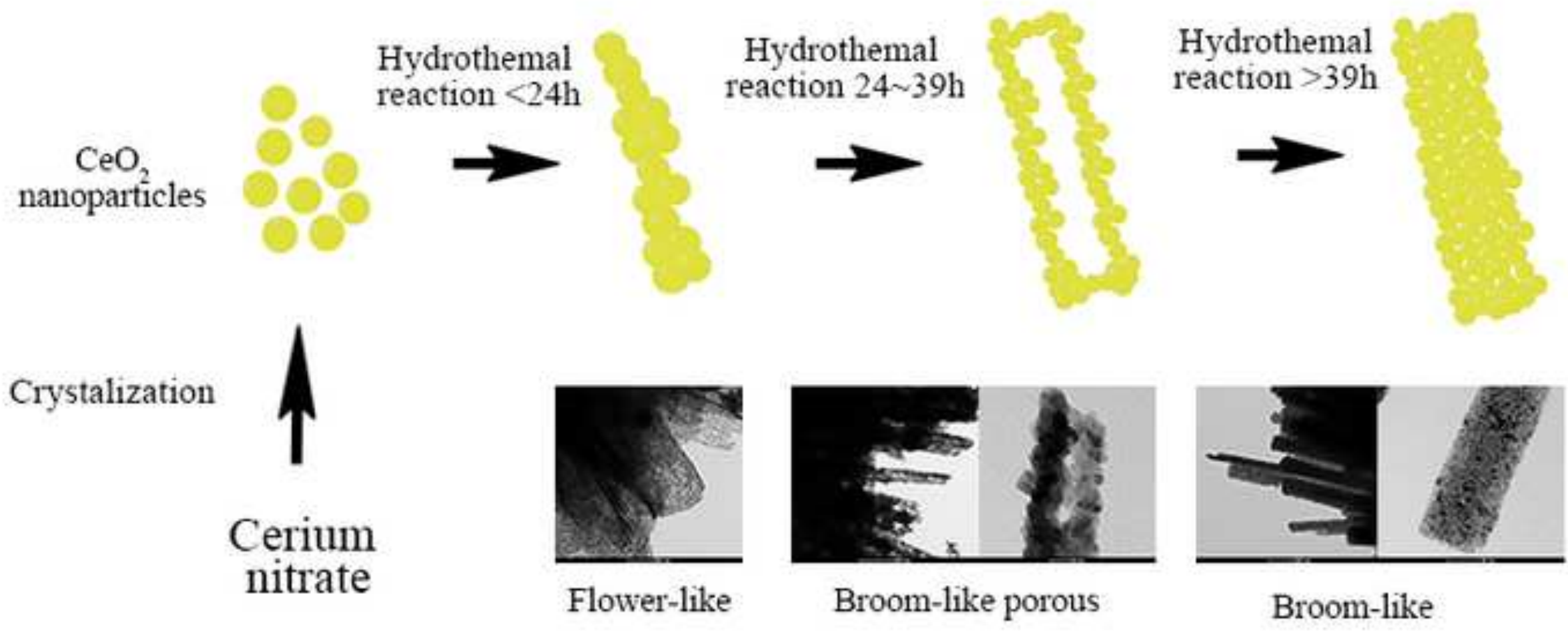




\begin{tabular}{cccccc}
\hline $\begin{array}{c}\text { Samples } \\
\begin{array}{c}\text { DTC:Ce-1.3:1 120 } \\
\text { under different time) }\end{array}\end{array}$ & $\begin{array}{c}\text { Lattice } \\
\text { parameters a }(\boldsymbol{\AA})\end{array}$ & $\begin{array}{c}\text { Calculated } \\
\text { grain size }(\mathbf{n m})\end{array}$ & $\begin{array}{c}\text { Particle } \\
\text { size }(\mathbf{n m})\end{array}$ & $\begin{array}{c}\text { Area } \\
\mathbf{R}_{\mathbf{D}} / \mathbf{A r e a}_{\mathbf{2}} \mathbf{F}_{\mathbf{2}} \\
\mathbf{( \% )}\end{array}$ & $\begin{array}{c}\mathbf{S}_{\text {BET }} \\
(\mathbf{m} \mathbf{2} / \mathbf{g})\end{array}$ \\
\hline $12 \mathrm{~h}$ & 5.413 & 4.51 & $\sim 10$ & 9.21 & 35.6 \\
$24 \mathrm{~h}$ & 5.417 & 4.60 & $\sim 10$ & 9.46 & 46.9 \\
$39 \mathrm{~h}$ & 5.423 & 4.50 & $\sim 5$ & 9.67 & 166.1 \\
$48 \mathrm{~h}$ & 5.415 & 5.52 & $\sim 10$ & 9.24 & 30.4 \\
\hline
\end{tabular}




\section{Graphical abstract}

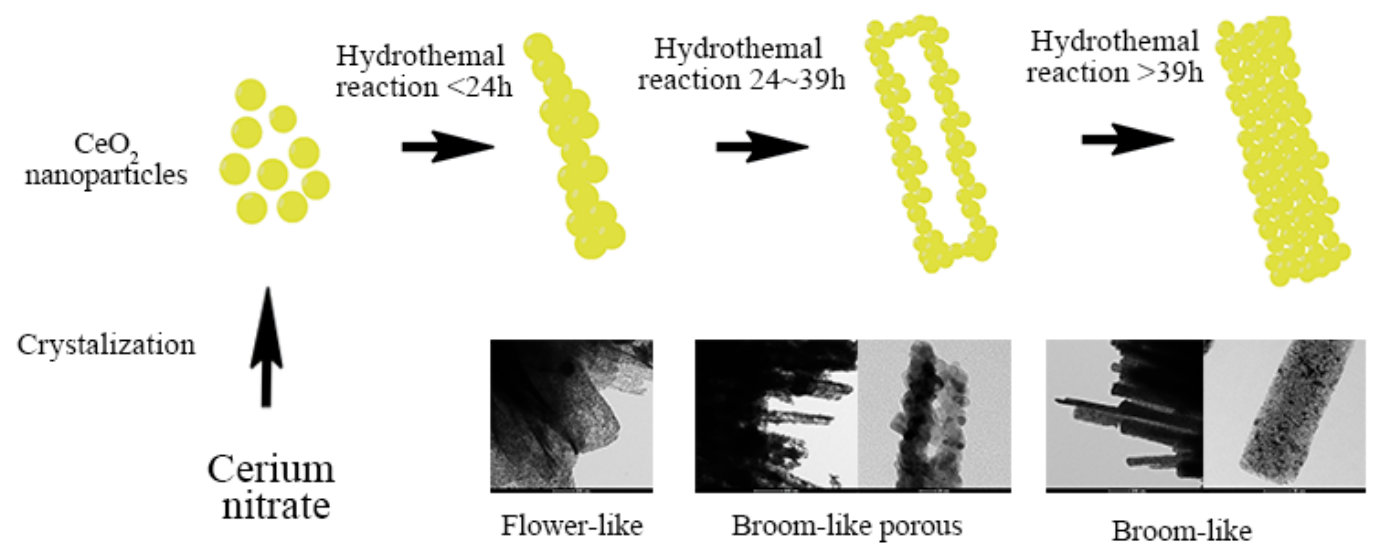

